\title{
Sexual Compulsivity Among Men in a Decentralized MSM Community of the Midwestern United States
}

\author{
Sonya Satinsky, M.P.H., Christopher Fisher, M.A., Nathan Stupiansky, M.S., Brian Dodge, Ph.D., M.S., \\ Andreia Alexander, M.P.H., Debby Herbenick, Ph.D., M.P.H., and Michael Reece, Ph.D., M.P.H.
}

\begin{abstract}
Among men who have sex with men (MSM), sexual compulsivity has been associated with higher frequencies of sexual behaviors that may increase risk for transmission of HIV and other sexually transmitted infections (STI). In a Midwestern region where social and community resources for MSM are relatively diffuse, the patterns of partner-seeking and sexual behavior, and their relations to sexual compulsivity, may be different than findings from most other assessments of men in large urban areas. Using a community-based participatory approach (CBPR) and a cross-sectional survey, quantitative data were collected between November 2006 and January 2007 from 504 men related to sexual compulsivity, sexual partner-seeking, and sexual behavior. We sought to explore sexual behaviors in venues where men reported meeting sexual partners, based on their level of compulsivity. Venues that could be characterized as "sexualized" were better predictors of higher sexual compulsivity scores among men than those that are "social" in nature. Men who were higher in compulsivity reported patterns of saturating sexualized venues in order to find sexual partners. Given the unique patterns of sexual partner-seeking in this area, interventions to decrease sexual risk-taking should take into account that men who have a higher propensity for sexual compulsivity are visiting multiple venues, and prevention messages need to be tailored to be consistent across these contexts. In addition, these may need to be differentially designed based on the specific environment in which they are to be delivered.
\end{abstract}

\section{Introduction}

S EXUAL COMPUlsivity has been characterized as a consistent pattern of sexually oriented activities that occur at escalating levels and have the potential to result in negative consequences to the self and/or others. ${ }^{1-5}$ Individuals who score higher on measures of sexually compulsivity often exhibit a preoccupation with sex and a lack of control over their sexual impulses. ${ }^{6}$ In previous research, the construct of sexual compulsivity has been associated with higher reported frequencies of sexual behaviors, particularly multiple sexual partners and unprotected intercourse with both primary and casual sexual partners. Given that these behaviors may increase the risk for negative sexual health outcomes, particularly HIV and other sexually transmissible infections (STI), sexual compulsivity has been given considerable attention in the HIV/STI literature for its associations with these behaviors. ${ }^{1,3,4,7-20}$ In particular, there has been an emphasis on understanding relations between sexual compulsivity and sexual behaviors among individuals living with HIV. Previous research has found that men living with HIV who score higher on a measure of sexual compulsivity are more likely than men who score lower to report engaging in unprotected intercourse with multiple sex partners, engaging in more frequent unprotected sex acts, using more illicit drugs concurrent with their sexual acts, and engaging in more unprotected anal and vaginal intercourse with partners of unknown- or HIV-positive sexual health status. ${ }^{3,14,15,19,21-24}$

Most previous studies have assessed sexual compulsivity using the Sexual Compulsivity Scale. ${ }^{16}$ Research has been conducted using this scale with HIV-positive samples, ${ }^{14,19}$ heterosexual samples, ${ }^{1,13,25}$ and clinical samples of individuals seeking treatment for sexually transmitted infections. ${ }^{26}$ The scale has been previously validated for use with men who have sex with men (MSM) in multiple samples. 3,16,20,21,26-32 Previous studies of sexual compulsivity in 
men have found mean scores between 1.80 and 2.06 on a scale of 1 to 4 with 4 being highly compulsive. 1,3,18,21,28 The current study marks an attempt to investigate sexual compulsivity in a community-based sample of MSM in a region of the United States that is characterized by diffuse and decentralized MSM resources.

\section{Study context}

This study was conducted in Indianapolis, Indiana, a Midwestern city in the United States with relatively limited resources for MSM, given that it has no organized community center for gay, lesbian, bisexual, and transgender (GLBT) individuals, has limited community-based venues that are GLBT identified, and has a limited number of social resources that are found in many cities of comparable size. This is compared to more sizeable GLBT communities that have organized themselves and that are known to be used by MSM for both social and sexual interactions (e.g., gay bars, neighborhoods, recreational organizations, and GLBT media).

A community-based participatory research (CBPR) framework was utilized to guide this study in an attempt to tap into the relatively diffuse MSM community. CBPR is a methodology that has been frequently used in sexual health research with hard-to-reach study populations such as transgender individuals, ${ }^{33}$ men who cruise for sex, ${ }^{3,18}$ and young immigrant Latino men. ${ }^{34}$ One aim of the CBPR paradigm is to make community partnerships central to research efforts and to encourage equitable relationships between communities, researchers, and research participants. ${ }^{35}$ In this study, a coalition of researchers, health care practitioners, and staff of community-based organizations conducting sexual health outreach came together to define not only study variables, but also to identify venues through which men who may be scattered across the metropolitan area might be reached. Community partners in this study reported that nonsexual social spaces for MSM in this area were lacking. In turn, they believed this may be related to a perception of a sense of isolation among MSM. Community members expressed that there were multiple sites for finding sexual partners or to have clinical screenings. However, these resources focused solely on sexual behavior or negative sexual health outcomes. There were very few physical spaces in metropolitan Indianapolis where community members felt that MSM could feel affirmed in their identity. Many studies of MSM have been conducted in large urban areas such as New York, San Francisco, Los Angeles, and Atlanta-cities that arguably have significant resources allocated toward the development and maintenance of centralized gay community efforts. ${ }^{3,29,36-45}$ Multiple studies of MSM in such urban areas have sought to determine whether the venue in which men are meeting their sexual partners has relations with sexual risk behaviors. ${ }^{38,43,46-51}$

Additionally, half of the counties in the state in which the study was conducted ${ }^{52}$ are classified as rural, with multiple additional counties that have regions also denoted as rural. However, until fiscal year 2007, the city of Indianapolis received no Title I money under the Ryan White CARE Act, a federal initiative that offers assistance to those living with HIV or AIDS. Although Ryan White-funded programs are focused on the delivery of HIV-related care in disproportionately impacted urban areas, they have also been quite re- sponsive to the delivery of culturally appropriate services to meet the unique social and cultural issues facing those disproportionately living with HIV. As a result, it is possible that Ryan White funding has helped to facilitate the growth of social spaces and sites of community cohesion for MSM in large urban areas. Many MSM-targeted organizations have been the recipients of these funds given their ability to provide services to these men. The lack of access to these federal monies in the city where this study was conducted may have also contributed to reduced development of social and cultural resources for MSM that has been observed in other areas where Ryan White Title I funds have been available for longer periods of time.

\section{Study aim}

Although assessments of MSM in large urban areas offer invaluable information into the character of their needs and behaviors, far less research has been conducted on those men who are without access to the significant MSM-specific resources that larger metropolitan areas offer. ${ }^{53-57}$ We hypothesize that, in the absence of multiple social and community venues for meeting sexual partners in the city where this study was conducted, men may exhibit high rates of visiting multiple sexualized venues to exhaust the opportunities for finding sexual partners. Men who score highly on the Sexual Compulsivity Scale may display even more frequent visitation to sexualized venues in the search for sexual partners, as well as potentially higher rates of sexual risk behavior. This study aims to gain a deeper understanding of which venues MSM with higher sexual compulsivity scores utilize to meet, interact with, and select sexual partners in order to determine where to effectively target interventions and outreach efforts.

\section{Methods}

\section{Background}

Adhering to the principles of CBPR, the researchers and the community partners collectively determined research questions, established study constructs, developed methods and location of recruitment, and constructed a survey instrument assessing various demographic, behavioral, and perceptual constructs of sexual health among MSM.

\section{Participant recruitment and data collection}

A total of nine sites were used for participant recruitment. Between November 2006 and January 2007, participants were recruited from sites identified by community members, including five relatively sexualized gay bars and two bath houses. In addition, Internet chat rooms and bulletin boards and a local "House Ball" event, a social gathering predominantly attended by young African American men, were used to recruit individuals. Bars, bath houses, and the "House Ball" were accessed in person by members of the community coalition and a member of the research team. Self-report surveys were administered using a pencil and paper instrument. Participants were male and over the age of 18. Each participant received a $\$ 10$ gift card to a national retail outlet in exchange for completing the survey. Internet participants completed an online version of the survey instrument and were offered the chance to win one of ten $\$ 100$ gift cards 
from a national retailer. All study protocols were reviewed and approved by the Committee on the Protection of $\mathrm{Hu}-$ man Subjects at Indiana University-Bloomington.

\section{Measures}

Participant characteristics. Participants provided data related to their age, gender (male, female, transgender male to female, transgender female to male, or other), race/ethnicity, level of education completed, employment status, and housing situation. Participants also responded to items related to their relationship status (married, partnered, divorced, widower, single, and other); whether they were currently dating someone or in a relationship (in a relationship with the same person longer than 6 months, 3-6 months, less than 6 months, dating more than one person, or not dating anyone); and whether they were currently in a sexual relationship (with one person, more than one person, sexually active, but don't consider myself in a sexual relationship, or currently not sexually active).

Sexual compulsivity. Sexual compulsivity was measured using the 10-item Sexual Compulsivity Scale developed by Kalichman and Rompa. ${ }^{16}$ Sample items include, "My sexual appetite has gotten in the way of my relationships," "I sometimes fail to meet my commitments and responsibilities because of my sexual behaviors," and "I feel that my sexual thoughts and feelings are stronger than I am." The items were measured on a four-point Likert-type scale ranging from 1 (never) to 4 (always). ${ }^{15}$ The reliability of the sexual compulsivity scale among this sample was high $(\alpha=0.90)$.

Substance use behaviors. Substance use behaviors were measured using a list of 13 commonly used substances, including alcohol, sexual enhancements such as Viagra, inhalants (such as poppers), marijuana (pot), and crystal methamphetamine. Participants were asked to indicate whether or not they had used the drug in the past 90 days. Participants were also asked whether they had ever been told by a health care provider that they had a drug-related or alcohol-related problem, or had received a diagnosis of sexual addiction. Response options for these questions were "yes," "no," and "unsure." Additionally, participants were asked whether they had sought mental health services or treatment for substance abuse in the previous year.

Sexual behaviors. Participants were asked to indicate whether or not they had engaged in specific unprotected sexual behaviors with both women and men over the previous 90 days. Unprotected behaviors included receptive anal intercourse, insertive anal intercourse, insertive vaginal intercourse, oral sex, and oral-anal contact. Additionally, participants reported whether or not they had visited or utilized sexualized venues and resources in the previous 90 days. These venues included sex-related Internet sites, telephone chat lines, cruising spots such as parks or restrooms, bath houses or sex clubs, and gay bars. Venue-specific sexual behaviors were assessed by asking participants to report whether they had engaged in sex with a partner who they had met at one of these venues. Frequency of sexual encounters with partners met via these locations was also reported.

\section{Statistical analyses}

Of 512 surveys obtained, 8 were designated as incomplete and removed. Using SPSS 14.0 (SPSS Inc., Chicago, IL), data were analyzed using $\chi^{2}$ analyses and logistic regression.

\section{Results}

\section{Participant characteristics}

Eighty percent of the sample $(n=400)$ identified as homosexual, $16 \%(n=80)$ identified as bisexual, and 24 additional men (5\%) identified variously as "queer" or "other." The mean age of the sample was 34.7 (standard deviation $[S D]=10.612)$. Seventy-nine percent of the sample identified as White $(n=400), 14 \%$ as African American/Black $(n=68)$, and the remaining $7 \%$ as other ethnicities (Table 1 ). This demographic breakdown had fewer Black/African American participants than is reflected in the larger racial profile of the

Table 1. Demographics

\begin{tabular}{|c|c|c|}
\hline & $\%$ & $\mathrm{n}$ \\
\hline \multicolumn{3}{|l|}{ Place of recruitment } \\
\hline Gay bars & $51 \%$ & 259 \\
\hline Internet chat rooms & $24 \%$ & 119 \\
\hline Bath houses & $19 \%$ & 97 \\
\hline House ball & $6 \%$ & 29 \\
\hline \multicolumn{3}{|l|}{ Sexual orientation } \\
\hline Homosexual & $80 \%$ & 400 \\
\hline Bisexual & $16 \%$ & 80 \\
\hline \multicolumn{3}{|l|}{ Race/ethnicity } \\
\hline White & $79 \%$ & 400 \\
\hline African-American/Black & $14 \%$ & 68 \\
\hline Asian/Pacific Islander & $2 \%$ & 16 \\
\hline Hispanic/Latino & $2 \%$ & 8 \\
\hline Other & $2 \%$ & 12 \\
\hline \multicolumn{3}{|l|}{ Area of residence } \\
\hline Indianapolis metropolitan area & $67 \%$ & 332 \\
\hline Indianapolis suburbs & $14 \%$ & 71 \\
\hline Indiana-not Indianapolis proper & $15 \%$ & 76 \\
\hline Outside of Indiana & $4 \%$ & 20 \\
\hline \multicolumn{3}{|l|}{ Relationship status } \\
\hline Single & $52 \%$ & 268 \\
\hline Partnered & $28 \%$ & 147 \\
\hline Divorced & $10 \%$ & 51 \\
\hline Married & $5 \%$ & 28 \\
\hline Widower & $2 \%$ & 11 \\
\hline Other & $3 \%$ & 13 \\
\hline \multicolumn{3}{|l|}{ Sexual Relationship Status } \\
\hline $\begin{array}{l}\text { Sexually active, but do not } \\
\text { consider themselves to be in a } \\
\text { sexual relationship }\end{array}$ & $30 \%$ & 153 \\
\hline $\begin{array}{l}\text { In a sexual relationship with } \\
\text { only one person }\end{array}$ & $29 \%$ & 148 \\
\hline $\begin{array}{l}\text { Having sexual relationships } \\
\text { with more than one person }\end{array}$ & $21 \%$ & 105 \\
\hline Not currently sexually active & $19 \%$ & 98 \\
\hline \multicolumn{3}{|l|}{ Education } \\
\hline Some college & $82 \%$ & 409 \\
\hline Bachelor's degree & $49 \%$ & 243 \\
\hline Postgraduate degree & $19 \%$ & 93 \\
\hline \multicolumn{3}{|l|}{ Health insurance } \\
\hline Yes & $76 \%$ & 382 \\
\hline No & $24 \%$ & 122 \\
\hline
\end{tabular}


metropolitan area (14\% versus $25 \%)$; however, racial proportions for white, Hispanic/Latino, and Asian/Pacific Islander were comparable. The majority of participants lived within Indianapolis $(67 \%, n=332)$. The remaining participants resided in the Indianapolis suburbs $(14 \%, n=71)$ and in areas of the state outside the Indianapolis metropolitan area $(15 \%, n=76)$. Only $4 \%(n=20)$ lived outside of Indiana. The characteristics of participants are summarized in Table 1.

The majority of participants $(52 \%)$ were single $(n=268)$, $28 \%$ were in a partnered relationship $(n=147), 10 \%$ were divorced $(n=51), 5 \%$ were married $(n=28), 2 \%$ were widowers $(n=11)$, and the remaining $3 \%$ indicated they were in other types of relationships $(n=13)$.

Participants were asked about whether or not they were currently in a sexual relationship; $30 \%(n=153)$ reported that they were sexually active, but didn't consider themselves to be in a sexual relationship, $29 \%(n=148)$ of the sample was in a sexual relationship with only one person, $21 \%(n=105)$ were having sexual relationships with more than one person, and 19\% $(n=98)$ were not currently sexually active.

The majority of our sample was well educated: $82 \%$ had attended some college ( $n=409), 49 \%$ had earned a bachelor's degree $(n=243)$, and $19 \%$ reported achieving a postgraduate degree $(n=93)$. In addition, $76 \%$ of the sample reported having health insurance $(n=382)$.

\section{Sexual compulsivity}

Similar to other studies, men in this sample were classified as high- or low-in sexual compulsivity using an extreme score approach predefined by previous studies. ${ }^{14,19,21}$ Men scoring higher than one standard deviation above the mean were classified as high in sexual compulsivity, while those scoring at or below one standard deviation above the mean were classified as low in sexual compulsivity. For this sample $(n=504)$ the mean SCS score was $1.56(\mathrm{SD}=0.55) ; 12.3 \%$ of men were categorized as high in sexual compulsivity $(n=62)$.

\section{SCS correlates to demographics}

Participants with higher compulsivity scores were more likely than those with lower scores to report that they were in a sexual relationship with more than one person, or sexually active outside the context of a relationship, $\chi^{2}(3, N=$ $504)=22.382, p<0.001$. No other demographic variables including ethnicity, education, or income were statistically related to sexual compulsivity scores.

\section{SCS correlates to venues for meeting sexual partners}

Participants reported visiting multiple venues over the previous 90 days; $40.4 \%(n=191)$ of participants had visited gay-specific Internet sites as well as going to a gay bar. Twenty-one percent $(n=100)$ had visited gay-specific Internet sites, a gay bar, and a bath house in the previous 90 days. Men who scored higher on the SCS were more likely to have visited sexualized venues such as cruising spots, $\chi^{2}(1, N=$ $499)=21.768, p<0.001$, bath houses or sex clubs, $\chi^{2}(1, N=$ $501)=9.635, p<0.01$, and phone chat lines, $\chi^{2}(1, N=496)=$ $5.941, p<0.05$, in the previous 90 days. These results are summarized in Table 2.

Men who met sexual partners at sexualized venues such as Internet chat rooms, bath houses, and gay bars, were doing so at only one venue with the Internet being the top choice $(19.8 \%, n=94)$. Higher compulsivity men were also more likely to have had sex with someone they met at a cruising spot, $\chi^{2}(1, N=501)=23.691, p<0.001$, bath house or sex club, $\chi^{2}(1, N=502)=14.329, p<0.001$, or on a phone chat line, $\chi^{2}(1, N=501)=12.256, p<0.001$ (Table 2).

Logistic regression analyses were conducted to assess whether a participant's use of specific sexual venues was predictive of higher or lower compulsivity scores. Reporting finding a sexual partner in any of the venues was positively associated with higher SCS score. Reporting finding a sexual partner via gay bars, however, was much less predictive of higher SCS score. SCS scores as related to venue are presented in Table 3.

Regarding the venues in which men reported finding a sexual partner, we used multivariate analyses to determine a model of the constellation of venues that is predictive of higher sexual compulsivity scores. The best model for prediction of higher compulsivity score included Internet (odds ratio $[\mathrm{OR}]=2.247, p<0.01,95 \% \mathrm{CI}=1.288$ to 3.918 ), cruising spots $(\mathrm{OR}=3.270, p<0.001,95 \% \mathrm{CI}=1.708$ to 6.261$)$, and, marginally, bath house or sex club $(\mathrm{OR}=1.719, p<$

Table 2. Sexual Compulsivity by Venue

\begin{tabular}{|c|c|c|c|c|}
\hline & \multicolumn{2}{|c|}{ Sexual compulsivity } & \multirow[b]{2}{*}{$\chi^{2}$} & \multirow[b]{2}{*}{$\mathrm{p}$} \\
\hline & $\begin{array}{l}\text { High } \\
\text { n }(\%)\end{array}$ & $\begin{array}{c}\text { Low } \\
\text { n (\%) }\end{array}$ & & \\
\hline \multicolumn{5}{|c|}{ Sexual community participation } \\
\hline Cruising spot & $21(34 \%)$ & $51(12 \%)$ & 21.768 & 0.000 \\
\hline Bath house or sex club & $29(47 \%)$ & $121(28 \%)$ & 9.635 & 0.002 \\
\hline Phone chat line & $13(21 \%)$ & $45(10 \%)$ & 5.941 & 0.015 \\
\hline \multicolumn{5}{|c|}{ Venue specific sexual behaviors } \\
\hline Cruising spot & $18(29 \%)$ & $37(8 \%)$ & 23.691 & 0.000 \\
\hline Bath house or sex club & $27(44 \%)$ & $95(22 \%)$ & 14.329 & 0.000 \\
\hline Phone chat line & $8(13 \%)$ & $14(3 \%)$ & 12.256 & 0.000 \\
\hline Internet & $35(56 \%)$ & $151(34 \%)$ & 11.600 & 0.001 \\
\hline Gay bar & $26(42 \%)$ & $123(28 \%)$ & 5.089 & 0.024 \\
\hline
\end{tabular}


Table 3. Odds Ratio of High Sexual Compulsivity by Venue

\begin{tabular}{lcc}
\hline Use of venue & Odds ratio & $\mathrm{p}$ value \\
\hline Phone chat line & 4.51 & 0.003 \\
Cruising spot & 4.46 & 0.000 \\
Bath house or sex club & 2.81 & 0.000 \\
Internet & 2.5 & 0.000 \\
Gay bar & 1.25 & 0.003 \\
\hline
\end{tabular}

$0.10,95 \% \mathrm{CI}=0.954$ to 3.095$)$. When phone chat was added to this model, the finding was not statistically significant, implying that bath house or sex club visitors were also meeting their partners via Internet, phone chat lines, and cruising spots. Gay bars were not a useful addition to the predictive model, implying that having sex with someone met through a gay bar was not indicative or predictive of higher compulsivity score. Regardless of level of compulsivity, a high proportion of men reported meeting sexual partners in gay bars.

\section{SCS correlates to sexual behaviors without a condom}

Eighty percent of the total sample $(n=393)$ had engaged in oral sex without a condom with another man in the previous 90 days. This rate was higher among men scoring higher on the measure of sexual compulsivity, of which $85.48 \%(n=53)$ reported engaging in unprotected oral sex with another man in the previous 90 days. Participants reported engaging in both condomless insertive $(40.1 \%, n=202)$ and receptive $(37.7 \%, n=190)$ anal intercourse. Men who scored higher on the SCS were more likely to have been the insertive partner in anal sex without a condom with another man in the previous 90 days, $\chi^{2}(1, N=503)=9.522, p<0.01$. However, receptive condomless anal intercourse was not associated with higher scores on the SCS.

Of the total sample, $9.9 \%(n=50)$ had engaged in condomless vaginal intercourse in the previous 90 days, and $17 \%$ $(n=85)$ reported having performed unprotected oral sex on a woman. Men with higher levels of sexual compulsivity were more likely to have been the insertive partner in vaginal sex without a condom in the previous 90 days, $\chi^{2}(1, N=$ $502)=4.808, p<0.05$, and were also more likely to have engaged in oral sex without a condom or barrier with women than were men with lower levels of compulsivity, $\chi^{2}(1, N=$ 501) $=7.363, p<0.01$.

Sexual behaviors associated with sex work were relatively small for our sample; $4.6 \%(n=23)$ had sexual interactions with a sex worker in the past 90 days and $4.4 \%(n=22)$ had paid money or given drugs in exchange for sex. Participants with higher sexual compulsivity scores were more likely to have engaged in transactional sex: they were significantly more likely to have engaged in sex with a prostitute or sex worker during the past 90 days, $\chi^{2}(1, N=499)=21.437, p<$ 0.001 , and were more likely to have paid money or given drugs to someone for sex during the same period than were men with lower levels of sexual compulsivity, $\chi^{2}(1, N=$ 502) $=17.393, p<0.001$.

\section{SCS correlates to mental health and substance use}

A small portion of the sample $(10 \%, n=53)$ had accessed mental health or substance abuse services in the past year. There was no significant difference between higher and lower sexual compulsivity groups when asked if they had sought mental health services or treatment for substance abuse in the past year, despite differences in reported diagnoses of these problems by a health care provider. Regarding health diagnoses, men with higher compulsivity scores were more likely to have been told by a health care provider that they have had a lifetime occurrence of sexual addiction, $\chi^{2}(1, N=480)=52.374, p<0.001$, followed by drug-related problems, $\chi^{2}(1, N=480)=16.763, p<0.001$, and alcohol-related problems, $\chi^{2}(1, N=481)=9.811, p<0.01$.

When asked about use of specific substances in the previous 90 days, the most frequently reported substances included alcohol $(57.7 \%, n=291)$, marijuana $(20.0 \%, n=101)$, and inhalants such as poppers, snappers, or whippets $(19 \%$, $n=96)$. Men who scored higher on the SCS were more likely to use marijuana than men who scored lower, $\chi^{2}(1, N=$ $503)=4.962, p<0.05$. Thirty-one percent of higher sexual compulsivity men $(n=19)$ reported using marijuana in the last 90 days, compared with $19 \%$ of low SCS men $(n=82)$. This pattern held true also for inhalants. Men with higher compulsivity scores were more likely to report using inhalants during the previous 90 days than men with low SCS scores, $\chi^{2}(1, N=498)=7.724, p<0.01$. Thirty-two percent of high SCS men $(n=20)$ reported using inhalants in the last 90 days, compared to $17 \%$ of low SCS men $(n=76)$. More than half of our total sample $(58 \%, n=291)$ reported using alcohol to the point of intoxication within the previous 90 days. There was no difference in alcohol consumption based on sexual compulsivity scores. Reported use of crystal methamphetamine use was not statistically different between groups, which may be reflective of very low incidence of reported methamphetamine use $(0.06 \%, n=31)$ in this sample.

\section{DISCUSSION}

As hypothesized, a pattern emerged regarding the venues in which men reported meeting sex partners, based on their level of sexual compulsivity. It appears that men who are higher in compulsivity were reporting a pattern of saturating sexualized venues in our region in order to find sexual partners. This may be a function of the dearth of venues in our region that might offer MSM the ability to meet sexual partners. While the majority of our data collection was conducted in gay bars and via the Internet, our results showed that gay bars were not the most significant venue for men to find partners. Gay bars could be conceptualized as less sexually charged environments than bath houses or cruising spots. Venues that can be characterized as more sexualized were better predictors of higher sexual compulsivity among men who reported finding sexual partners there. Regarding specific sexual behaviors, the only differences between compulsivity groups was that highly compulsive men were more likely to engage in condomless insertive anal and vaginal sex. In the state in which our study was conducted, rates of HIV, even among MSM, are low in comparison to national averages. However, rates of STIs such as syphilis are among the highest. ${ }^{58}$ Thus, it is possible that insertive condomless 
anal or vaginal sex by these men could lead to the transmission of STIs to their partners.

Despite being in a region characterized by a lack of social and community resources which could be related to an increase in behavior that might be interpreted as sexually compulsive, this non-clinical sample had a lower mean SCS score $(M=1.56, \mathrm{SD}=0.55)$ than other studies on MSM have found, as well as a lower mean score than a sample of heterosexual college students $(M=1.64, \mathrm{SD}=0.40) .{ }^{1}$ It is possible that in contrast to studies of MSM conducted in settings such as STI clinics or substance abuse facilities, MSM in a Midwestern city may have lower overall mean scores of sexual compulsivity in comparison to men in other areas. In addition, reported methamphetamine use among our participants was low, in contrast to comparable studies of MSM in other areas of the country. ${ }^{59-63}$ A CBPR paradigm was crucial in reaching our study participants. A series of meetings was conducted between the research team, community practitioners, and business owners to develop and refine the study instrument. In discussing participant recruitment, community partners identified venues in which they were familiar with, or in which they had already been conducting outreach activities. Without the perspective of those already working with MSM in the field, it would have been extremely difficult to reach these men in a region lacking centralized nonsexualized community and social spaces.

The community coalition involved with this study specifically identified sexual compulsivity as a construct they were interested in exploring, in order to target their interventions. Given the unique pattern of sexual partner-seeking in this region, interventions to decrease sexual risk-taking should take into account that men are visiting multiple venues. Therefore, these men may be exposed to intervention messages in several locations. A suggestion might be that these intervention messages should be consistent across contexts, but may have to be delivered differentially based on the specific environment in which they are delivered. For this diffuse community, however, the Internet was the most popular site for meeting sexual partners and thus should be a primary target should funding be limited. Several limitations to this study must be acknowledged. While the sample of men was diverse, venue-based convenience sampling was used to recruit them. Unlike other studies in large urban areas where venue-based sampling results in men who come from diverse geographic areas, ${ }^{64} 96 \%$ of men in this sample lived in the state of Indiana, with $81 \%$ of them residing in the metropolitan area of Indianapolis. While this provides valuable data for those working to develop programs for men who reside in the state, it did not allow for us to consider the characteristics of those who may travel from other areas to attend this city's few MSM venues. Given that Indiana is situated in a region of the country surrounded by large rural areas with few MSM resources, future studies in this region would benefit by attempts to also recruit men who travel from these rural areas and who may not be exposed to the HIV or STI interventions that are implemented within the city of Indianapolis. The choices of venues for meeting sexual partners were limited and may not have captured other unique environments where MSM can meet that we may not have tapped into. It is possible that the low numbers of men that indicated they had used phone chat lines or been to cruising spots and/or meeting sexual partners through these venues may have been low because these individuals are less likely to go to MSM bars, bath houses, or use the Internet. Also, with regard to sexual behaviors, we did not assess behaviors which included use of condoms or other barrier devices. Future studies should include such a measure.

A further area of study that could be explored for regions similar to ours is the concept of sexual community participation. Sexual community may be formed in the absence of non-sexually-related sites for community building, i.e., neighborhoods, community centers, or professional organizations. Even in areas where a community is not centralized via MSM-specific venues, men find ways to participate in a sexual community, and may be building social bonds via sexualized venues as they are what are readily available. Public health professionals in these geographical regions are presented with the unique challenge of assessing the nature of community cohesion and participation in areas where resources for MSM are fragmented. Research into the notion of sexual community participation could help to conceptualize how men who have sex with men relate to each other socially and sexually over a diffuse geographical region. Reaching these men via interventions to reduce the risk of negative sexual health outcomes may, indeed, be dependent on understanding how they find and interact with one another.

\section{REFERENCES}

1. Dodge B, Reece M, Cole SL, Sandfort TGM. Sexual compulsivity among heterosexual college students. J Sex Res 2004;41:343-350.as

2. Fischer B. Sexual addiction revisited. Addict Newsl 1995;2:27.

3. Reece M. Sexual compulsivity and HIV serostatus disclosure among men who have sex with men. Sex Addict Compulsivity 2003;10:1-11.

4. Reece M, Dodge B, McBride K. Sexual compulsivity: issues and challenges. In: McAnulty R, Burnette M, eds. Sex and Sexuality. London: Praeger Press, 2006, pp. 213-231.

5. Society for the Advancement of Sexual Health. Sexual addiction. http://sash.net/content/view/24/39/ (Last accessed December 6, 2007).

6. Gold SN, Heffner CL. Sexual addiction: Many conceptions, minimal data. Clin Psychol Rev 1998;18:367-381.

7. Bancroft J, Vukadinovic Z. Sexual addiction, sexual compulsivity, sexual impulsivity, or what? Toward a theoretical model. J Sex Res 2004;41:225-234.

8. Barth RJ, Kinder BN. The mislabeling of sexual impulsivity. J Sex Marital Ther 1987;13:15-23.

9. Carnes P. Contrary to Love: Helping the Sexual Addict. City Center, MN: Hazeldon, 1989.

10. Coleman E. The obsessive-compulsive model for describing compulsive sexual Am J Prev Psychiatry Neurol 1990;2:9-14.

11. Cooper A, Delmonico DL, Burg R. Cybersex users, abusers, and compulsives: New findings and implications. Sex Addict Compulsivity 2000;7:5-29.

12. Goodman A. Sexual addiction. In: Lowinson JH, Ruiz P, Millman RB, Langrod JG, eds. Substance Abuse: A Comprehensive Textbook, 4th ed. Philadelphia: Williams \& Wilkins, 2005, pp. 504-539.

13. Gullette DL, Lyons MA. Sexual sensation seeking, compulsivity, and HIV risk behaviors in college students. J Community Health Nurs 2005;22:47-60. 
14. Kalichman SC, Cain D. The relationship between indicators of sexual compulsivity and high risk sexual practices among men and women receiving services from a sexually transmitted infection clinic. I Sex Res 2004; 41:235-241.

15. Kalichman SC, Johnson JR, Adair V, Rompa D, Multhauf K, Kelly JA. Sexual sensation seeking: Scale development and predicting AIDS-risk behavior among homosexually active men. J Pers Assess 1994;62:385-397.

16. Kalichman SC, Rompa D. Sexual sensation seeking and sexual compulsivity scales: Reliability, validity, and predicting HIV risk behavior. J Pers Assess 1995;65:586-601.

17. McBride K, Reece M, Sander S. Predicting outcomes of sexual behavior. Intern J Sex Health 2008,19:51-62.

18. Reece M, Dodge B. A study in sexual health applying the principles of community-based participatory research. Arch Sex Behav 2004;33:235-247.

19. Reece M, Plate PL, Daughtry M. HIV prevention and sexual compulsivity: The need for an integrated strategy of public health and mental health. Sex Addict Compulsivity 2001;8: 157-167.

20. Semple SJ, Zians J, Grant I, Patterson TL. Sexual compulsivity in a sample of HIV-positive methamphetamine-using gay and bisexual men. AIDS Behav 2006;10:587-598.

21. Benotsch EG, Kalichman SC, Kelly JA. Sexual compulsivity and substance use in HIV-seropositive men who have sex with men: Prevalence and predictors of high-risk behaviors. Addict Behav 1999;24:857-868.

22. Benotsch EG, Kalichman SC, Pinkerton SD. Sexual compulsivity in HIV-positive men and women: Prevalence, predictors, and consequences of high-risk behaviors. Sex Addict Compulsivity 2001;8:83-99.

23. Bimbi DS, Nanin JE, Parsons JT, Vicioso KJ, Missildine W, Frost DM. Assessing gay and bisexual men's outcome expectancies for sexual risk under the influence of alcohol and drugs. Substance Use Misuse 2006;41:643-652.

24. Kalichman SC, Greenberg J, Abel GG. HIV-seropositive men who emerge in high-risk sexual behavior: Psychological characteristics and implications for prevention. $\underline{\text { AIDS Care }}$ 1997;9:441-450.

25. McBride K, Reece M. Predicting negative outcomes of sexuality using the Compulsive Sexual Behavior Inventory. Int J Sexual Health (in press).

26. Kalichman SC, Rompa D. The sexual compulsivity scale: Further development and use with HIV-positive persons. I Pers Assess 2001;76:379-395.

27. Grov C, Bamonte A, Fuentes A, Parsons JT, Bimbi DS, Morgenstern J. Exploring the Internet's role in sexual compulsivity and out of control sexual thoughts/behaviour: A qualitative study of gay and bisexual men in New York City. Cult Health Sex 2007:1-19.

28. Parsons JT, Bimbi D, Halkitis PN. Sexual compulsivity among gay/bisexual male escorts who advertise on the Internet. Sex Addict Compulsivity 2001;8:101-112.

29. Parsons JT, Kelly BC, Bimbi DS, Muench F, Morgenstern J. Accounting for the social triggers of sexual compulsivity. I Addict Dis 2007;26:5-16.

30. Parsons JT, Severino JP, Grov C, Bimbi DS, Morgenstern J. Internet use among gay and bisexual men with compulsive sexual behavior. Sex Addict Compulsivity 2007; 14:239-256.

31. Rosenmann A, Safir MP. Gay identity nonendorsement and the role of dissociative characteristics in a culturally diverse online sample of men who have sex with men. Sex Res Social Policy 2007;4:18-26.
32. Torres HL, Gore-Felton C. Compulsivity, substance use, and loneliness: The loneliness and sexual risk model (LSRM). Sex Addict Compulsivity 2007;14:63-75.

33. Clements-Nolle K, Bachrach A. Community based participatory research with a hidden population: The Transgender Community Health Project. In: Minkler M, Wallerstein N, eds. Community Based Participatory Research for Health. San Francisco, CA: Jossey-Bass, 2003, pp. 332-344.

34. Rhodes SD, Hergenrather KC, Wilkin A, Alegria-Ortega J, Montano J. Preventing HIV infection among young immigrant Latino men: Results from focus groups using community-based participatory research. INatl Med Assoc 2006; 98:564-573.

35. Minkler M, Wallerstein N. Community Based Participatory Research for Health. San Francisco: Jossey-Bass, 2003.

36. Grov C, Bimbi DS, Nanin JE, Parsons JT. Exploring racial and ethnic differences in recreational drug use among gay and bisexual men in New York City and Los Angeles. J Drug Educ 2006;36:105-123.

37. Grov C, DeBusk JA, Bimbi DS, Golub SA, Nanin JE, Parsons JT. Barebacking, the Internet, and harm reduction: An intercept survey with gay and bisexual men in Los Angeles and New York City. AIDS Behav 2007;11:527-536.

38. Grov C, Parsons JT, Bimbi DS. Sexual risk behavior and venues for meeting sex partners: An intercept survey of gay and bisexual men in LA and NYC. AIDS Behav 2007;11: 915-926.

39. Halkitis PN, Parsons JT. Recreational drug use and HIV-risk sexual behavior among men frequenting gay social venues. I Gay Lesbian Soc Services 2002;14:19.

40. Halkitis PN, Wilton L, Parsons JT, Hopp C. Correlates of sexual risk-taking behaviour among HIV seropositive gay men in concordant primary partner relationships. Psychol Health Med 2004;9:99-113.

41. O'Leary A, Purcell DW, Remien RH, Fisher HE, Spikes PS. Characteristics of bisexually active men in the Seropositive Urban Mens' Study (SUMS). AIDS Care 2007; 19:940-946.

42. Osmond DH, Pollack LM, Paul JP, Catania JA. Changes in prevalence of HIV infection and sexual risk behavior in men who have sex with men in San Francisco: 1997-2002. Am J Public Health 2007;97:1677-1683.

43. Parsons JT, Halkitis PN. Sexual and drug-using practices of HIV-positive men who frequent public and commercial sex environments. AIDS Care 2002;14:815-826.

44. Parsons JT, Vicioso K, Kutnick A, Punzalan JC, Halkitis PN, Velasquez MM. Alcohol use and stigmatized sexual practices of HIV seropositive gay and bisexual men. Addict Behav 2004;29:1045-1051.

45. Reece M, Dodge B, Herbenick D, Fisher C, Alexander A, Satinsky S. Experiences of condom fit and feel among African-American men who have sex with men. Sex Transm Infect 2007;83:454-457.

46. Aynalem G, Smith L, Bemis C, Taylor M, Hawkins K, Kerndt P. Commercial sex venues: A closer look at their impact on the syphilis and HIV epidemics among men who have sex with men. Sex Transm Infect 2006;82:439-443.

47. Binson D, Woods WJ, Pollack L, Paul J, Stall R, Catania JA. Differential HIV risk in bathhouse and public cruising areas. Am J Public Health 2001;91:1482-1486.

48. de Wit JB, de Vroome EM, Sandfort TG, van Griensven GJ. Homosexual encounters in different venues. Int J STD AIDS Feb 1997;8:130-134.

49. Fisher HH, Purcell DW, Hoff CC, Parsons JT, O'Leary A. Recruitment source and behavioral risk patterns of HIV-posi- 
tive men who have sex with men. AIDS Behav 2006;10:553561.

50. Frankis J, Flowers P. Men who have sex with men (MSM) in public sex environments (PSEs): A systematic review of quantitative literature. AIDS Care 2005;17:273-288.

51. Qiang X, Tholandi M, Osmond DH, et al. The effect of venue sampling on estimates of HIV prevalence and sexual risk behaviors in men who have sex with men. Sex Transm Dis 2006;33:545-550.

52. Indiana State Office of Rural Health. Rural Counties and Designated Eligible Census Tracts in Metropolitan Counties. www.in.gov/isdh/publications / partner_rel/rural_health/ county_lists.htm\#section2 (Last accessed December 6, 2007).

53. Boulden W. Gay men living in a rural environment. J Gay Lesbian Soc Services 2001;12(3-4):63-75.

54. Foster S. Rural lesbians and gays: Public perceptions, worker perceptions, and service delivery. J Gay Lesbian Soc Services 1997;7:23-35.

55. Lindhorst T. Lesbians and gay men in the country: Practice implications for rural social workers. J Gay Lesbian Soc Services 1997;7:1-12.

56. Mancoske RJ. Rural HIV/AIDS social services for gays and lesbians. In: Smith JD, Mancoske RJ, eds. Rural Gays and Lesbians: Building on the Strengths of Communities. New York: Haworth Press, 1997:37-52.

57. Smith J, Mancoske B. Rural Gays and Lesbians: Building on the Strengths of Communities. Binghamton, NY: Haworth Press, 1997.

58. Centers for Disease Control and Prevention. Gonorrhea and Syphilis Rates by City, 1999. http://imaps.indygov.org/ ed $\% 5 F$ portal $/$ template.asp?page $=$ demographics. (Last accessed November 27, 2007).
59. Rhodes S, Hergenrather KC, Yee LJ, et al. Characteristics of a sample of men who have sex with men, recruited from gay bars and Internet chat rooms, who report methamphetamine use. AIDS Patient Care STDs 2007;21:575-583.

60. Buchacz K, McFarland W, Kellogg TA, et al. Amphetamine use is associated with increased HIV incidence among men who have sex with men in San Francisco. AIDS 2005;19: 1423-1424.

61. Purcell DW, Moss S, Remien RH, Woods WJ, Parsons JT. Illicit substance use, sexual risk, and HIV-positive gay and bisexual men: Differences by serostatus of casual partners. AIDS 2005;19(Suppl 1):S37-47.

62. Halkitis PN, Parsons JT, Stirratt MJ. A double epidemic: Crystal methamphetamine drug use in relation to HIV transmission among gay men. I Homosex 2001;41:17-35.

63. Hirschfeld S, Remien RH, Humberstone M, Walavalkar I, Chiasson MA. Substance use and high-risk sex among men who have sex with men: A national online study in the USA. AIDS Care 2004;1:1036-1047.

64. Benotsch EG, Mikytuck JJ, Ragsdale K, Pinkerton SD. Sexual risk and HIV acquisition among men who have sex with men travelers to Key West, Florida: A mathematical modeling analysis. AIDS Patient Care STDs 2006;20:549-556.

Address reprint requests to: Michael Reece, Ph.D., M.P.H. Center for Sexual Health Promotion

HPER 116

Indiana University Bloomington, IN 47405

E-mail: mireece@indiana.edu 


\section{This article has been cited by:}

1. Brian Dodge, Phillip W. Schnarrs, Michael Reece, Omar Martinez, Gabriel Goncalves, David Malebranche, Barbara Pol, Ryan Nix, J. Dennis Fortenberry. 2013. Sexual Behaviors and Experiences Among Behaviorally Bisexual Men in the Midwestern United States. Archives of Sexual Bebavior 42:2, 247-256. [CrossRef]

2. Brian Dodge, Phillip W. Schnarrs, Michael Reece, Omar Martinez, Gabriel Goncalves, David Malebranche, Barbara Van Der Pol, Ryan Nix, J. Dennis Fortenberry. 2012. Individual and Social Factors Related to Mental Health Concerns Among Bisexual Men in the Midwestern United States. Journal of Bisexuality 12:2, 223-245. [CrossRef]

3. Paul J. Wright, Ashley K. Randall, Javette Grace Hayes. 2012. Predicting the Condom Assertiveness of Collegiate Females in the United States From the Expanded Health Belief Model. International Journal of Sexual Health 24:2, 137-153. [CrossRef]

4. Phillip W. Schnarrs, Brian Dodge, Michael Reece, Gabriel Goncalves, Omar Martinez, Barbara Van Der Pol, David Malebranche, Maresa Murray, Ryan Nix, J. Dennis Fortenberry. 2012. Subjective Sexual Experiences of Behaviorally Bisexual Men in the Midwestern United States: Sexual Attraction, Sexual Behaviors and Condom Use. Journal of Bisexuality 12:2, 246-282. [CrossRef]

5. Hugh Klein. 2011. Felching Among Men Who Engage in Barebacking (Unprotected Anal Sex). Archives of Sexual Bebavior . [CrossRef]

6. Joshua G. Rosenberger, Brian Dodge, Barbara Pol, Michael Reece, Debby Herbenick, J. Dennis Fortenberry. 2011. Reactions to Self-Sampling for Ano-Rectal Sexually Transmitted Infections Among Men Who Have Sex with Men: A Qualitative Study. Archives of Sexual Bebavior 40:2, 281-288. [CrossRef]

7. Matthew J. Mimiaga, Sari L. Reisner, Sean Bland, Kevin Cranston, Deborah Isenberg, Maura A. Driscoll, Rodney VanDerwarker, Kenneth H. Mayer. 2010. "It's a Quick Way to Get What You Want": A Formative Exploration of HIV Risk Among Urban Massachusetts Men Who Have Sex with Men Who Attend Sex Parties. AIDS Patient Care and STDs 24:10, 659-674. [Abstract] [Full Text HTML] [Full Text PDF] [Full Text PDF with Links]

8. Phillip W. Schnarrs, Joshua G. Rosenberger, Sonya Satinsky, Emily Brinegar, Jill Stowers, Brian Dodge, Michael Reece. 2010. Sexual Compulsivity, the Internet, and Sexual Behaviors Among Men in a Rural Area of the United States. AIDS Patient Care and STDs 24:9, 563-569. [Abstract] [Full Text HTML] [Full Text PDF] [Full Text PDF with Links]

9. Madeleine U. Shalowitz, Anthony Isacco, Nora Barquin, Elizabeth Clark-Kauffman, Patti Delger, Devon Nelson, Anthony Quinn, Kimberly A. Wagenaar. 2009. Community-Based Participatory Research: A Review of the Literature With Strategies for Community Engagement. Journal of Developmental \& Bebavioral Pediatrics 30:4, 350-361. [CrossRef]

10. Lisette Kuyper, John de Wit, Titia Heijman, Han Fennema, Jan van Bergen, Ine Vanwesenbeeck. 2009. Influencing Risk Behavior of Sexually Transmitted Infection Clinic Visitors: Efficacy of a New Methodology of Motivational Preventive Counseling. AIDS Patient Care and STDs 23:6, 423-431. [Abstract] [Full Text PDF] [Full Text PDF with Links] 